\title{
Communicating by doing something else
}

\author{
Alex Davies (davies@ut.ee)
}

\section{Kaplan's thesis}

David Kaplan (1989) introduced us to the notion of "character." A character is a function from contexts to contents where the content in question depends on the type of linguistic expression in question (e.g. 1989, p.505): for a sentence, the content is a truth-condition; for a predicate, the content is a satisfaction condition; for a proper name, the content is an object (if this sounds like an odd way to talk, see the footnote). ${ }^{1}$ For example, the word "I" might have the following character: the content of "I" in context $\mathrm{C}$ is the speaker of "I" in context C." Given some circumstance of which to speak, a character fixes the extension of an expression when supplied with a context.

Why care about character? According to Kaplan:

...there is [a] sense of meaning in which, absent lexical or syntactical ambiguities, two occurrences of the same word or phrase must mean the same. (Otherwise how could we learn and communicate with language?) This sense of meaning - which I call character - is what determines the content of an occurrence of a word or phrase in a given context. (1989, p. 524)

Kaplan's "how could...?" betrays the belief that a word or phrase must have a context invariant meaning which determines the content of an occurrence of that word or phrase in a given context, if linguistic communication is possible. This thesis about what is required for

1 We can distinguish between propositional and non-propositional theories of "meaning" (cf. Speaks 2014). I use the scare-quotes around "meaning" because in what follows, it will be an open question whether these theories are theories of meaning in the sense of "meaning" with which we will be concerned. A propositional theory of "meaning" assigns objects to context-insensitive expressions. These objects are diverse. For example, for sentences they will be functions from circumstances of evaluation to truth-values (AKA propositions) but for predicates they will be functions from circumstances of evaluation to sets of objects (AKA properties). A non-propositional theory doesn't assign objects to linguistic expressions. Again, for example, for a sentence, it describes a condition under which that sentence is true, and, for a predicate, it describes a condition under which an object satisfies that predicate. In the current paper, when I talk of content I am talking about the objects assigned to expressions in a propositional theory of "meaning." However, these are ways of specifying what is specified by a non-propositional theory. For example, a proposition (a function from circumstances of evaluation to truth-values) describes a condition under which a sentence would be true, if that sentence expressed that proposition: viz. whatever is so in each circumstance of evaluation in which the proposition maps to the truth-value true. For this reason, I talk about the content of a sentence as a truth-condition; mutatis mutandis other kinds of linguistic expression. Finally, I stress that the words "proposition" and "property" are sometimes used to speak of what will, in this paper, be called "meaning." When used in this sense, they are not being used as they are used in describing a theory of "meaning" (e.g. to speak of a function from circumstances of evaluation to truth-values and to speak of a function from circumstances of evaluation to objects, respectively). On this ambiguity, see (Travis, 1978, p. 421). The assumption that these two senses of "proposition" and "property" are co-extensive is substantive and may be false. I discuss this further in section 2 .

2 The language used to describe the content and character of an expression may itself be context-sensitive. If it is then it is possible that the context in which such descriptions are made doesn't fix what counts as being the content or character in question. See Gross 2005 and Travis 1978; 1981 for discussion of this concern. In the current paper I will assume that this problem doesn't arise. 
linguistic communication will be our focus in what follows. Some prefatory remarks are needed before I can make a canonical statement of the thesis.

Let's say that linguistic expressions are words of a language and complex expressions (including sentences) formed from them. In the quoted passage, Kaplan uses "character" to speak of context-invariant meaning and to speak of functions from contexts to contents (i.e. "...what determines the content of an occurrence of a word or phrase in a given context"), as if these were one and the same. In the opening paragraph, I introduced "character" to speak of only the latter. If I were to follow Kaplan in his terminological choice, I wouldn't have an expression to speak of functions from contexts to contents which doesn't presuppose that context-invariant meanings are such functions. Since I don't want to make this presupposition myself, it will be useful to use the more technical term "character" to speak of the more technical thing only (viz. functions from contexts to contents) and the less technical term "meaning" to speak of the less technical thing only (viz. context-invariant meanings of expressions). Linguistic communication involves the production of linguistic expressions by a speaker to a hearer, where both speaker and hearer speak the same language. At the very least, the possibility of successful linguistic communication requires that a hearer be in a position to know what proposition a speaker intends by her sentence when the hearer observes that speaker utter the sentence (in context). ${ }^{3}$

With these prefatory remarks made, we can say that in the quoted passage, Kaplan is in effect putting forward the following thesis:

\section{Kaplan's Thesis}

It is possible for a hearer to be in a position to know what proposition a speaker intends by her sentence when the hearer observes that speaker utter the sentence (in context) only if the meaning of a linguistic expression is a character.

My interest in Kaplan's thesis lies in the fact that it can be used to construct an argument against a thesis championed by Charles Travis; namely, occasion-sensitivity. According to one straightforward statement of occasion-sensitivity:

....in the general case, expressions don't have definite characters. A fortiori, they don't have contents even on occasion, though what is said via them might. The meaning of an expression is nothing like a content. (Travis, 1978, p. 429 fn.9) ${ }^{4}$

When Travis denies that expressions have characters, he's denying that their meanings are characters. ${ }^{5}$ So occasion-sensitivity is the rejection of a reductive hypothesis:

3 This is not to say that the content of an expression in context is what a speaker intends it to be.

4 Other statements can be found in: Travis, 1985, p. 188, Travis, 1996, p. 94), Travis, 1997, p. 112, Travis 2000:xi, Travis 2006a, p. 13ff., and Travis, 2008, pp.2-3. Many of these statements don't include the explicit denial that linguistic expressions have characters - they focus on contents. A very careful and more general statement of the view, one which makes it clear that Travis intends the view to apply not just to linguistic expressions but to any item which can bear meanings and contents, can be found in the first chapter of Travis 1989.

5 One might think that, trivially, linguistic expressions have characters because there'll always be some way of mapping contexts of use to contents for all actual contents an expression ever ends up having. However, the proposal that the meaning of an expression is a character is a proposal about something which guides proper use. It is not a proposal about the possibility of producing a summary of the history of an expression's use. For discussion see (Travis 1978) and (Travis 1981). 


\section{Character Hypothesis}

The meaning of a linguistic expression is a character.

The aforementioned argument against occasion-sensitivity is an argument in favour of the character hypothesis. It is as follows:

\section{Argument against occasion-sensitivity}

1) It is possible for a hearer to be in a position to know what proposition a speaker intends by her sentence when the hearer observes that speaker utter the sentence (in context) only if the meaning of a linguistic expression is a character. (Kaplan's thesis)

2) It is possible for a hearer to be in a position to know what proposition a speaker intends by her sentence when the hearer observes that speaker utter the sentence (in context). (assumption)

Therefore:

3) The meaning of a linguistic expression is a character (from (1), (2) and modus ponens).

It's hard to imagine someone who would deny the second premise-they undermine themselves in telling you it's wrong. Moreover, it seems that many will grant the first premise. Kaplan is far from the only one to commit to Kaplan's thesis. Stenius (1967, p. 258) claims that if the meanings of linguistic expressions weren't (items that play the role of) characters then linguistic communication would be impossible. Lewis (1969, pp. 49-51) assumes that the meaning of an expression is something that functions as a character and that this meaning constitutes the only solution to a coordination problem between would-be communicators. ${ }^{6}$ Never mind precisely what a coordination problem is. What matters for present purposes is that if there is a coordination problem then there is a problem of ensuring that the content a speaker intends by her expressions when she utters them is what a hearer would take their content to be. So insofar as there is a coordination problem, there is no successful linguistic communication. In response to Davidson's (1986) declaration that there is no such thing as a language (roughly, and in the terms of this paper, a shared system of linguistic expressions with meanings that fix the expressions' contents in context), Dummett (1986, p. 474; 1994), Hornsby (2009, p. 114) and Reimer (2004, p. 324) object that the meanings of linguistic expressions (what you learn when you learn the language) must do what Davidson says they don't because if they didn't linguistic communication would not be possible. In response to Travis' proposal that occasion-sensitivity might be true, Stanley (2007, pp. 8-9) charges that if Travis were right, then action based on communication could not be coordinated in the way it evidently is (implicitly because successful linguistic communication would not be possible). ${ }^{7}$

6 Why think he thinks this is the only solution? Firstly, Lewis only discusses the solution of a communicative coordination problem by the adoption of a convention, which suggests that he thinks that this is the only way to solve it. Secondly, there's the following remark: "...so long as even two languages are humanly possible, it must be by convention that a population chooses to use one or the other." (ibid, p.50)

7 Recanati $(2004 ; 2010)$ and Sperber and Wilson (1986) are often classified under the same banner as Travis vis a vis their views on meaning. This is a mistake for reasons which Travis (1990) explains in relation to 
But then many will accept premises which entail that occasion-sensitivity is false. A problem for anyone wishing to get occasion-sensitivity more widespread acceptance is the acceptance of these premises. To my knowledge, Travis doesn't discuss the Argument against Occasionsensitivity. ${ }^{8}$ This is reasonable, given just how little argument typically goes into supporting Kaplan's thesis. My aim in the present paper is to argue against Kaplan's thesis. I aim to show that it doesn't follow simply from the denial of the character hypothesis that linguistic communication is not possible.

I'll begin in section 2 by providing a more precise specification of occasion-sensitivity. In section 3, I'll show that the character hypothesis implies that the content of an expression in context is a conventional feature of that expression. In section 4, I will describe a kind of property which objects can have if they are employed in a certain kind of activity - what I will call a "practico-normative property." Practico-normative properties are not conventional properties. In section 5, I put forward the hypothesis that expressions in context have contents which are practico-normative properties (I call these practico-normative contents). In section 6, I describe a way in which successful linguistic communication could take place ("the Evans method") which makes use of the practico-normative contents of expressions in context. This way of communicating doesn't require any conventional feature of linguistic expressions to fix the content of those expressions in context and therefore doesn't require the character hypothesis to be true. Hence, this possibility shows that Kaplan's thesis is false and that the Argument against Occasion-sensitivity is unsound. In section 7, I argue that the Evans method also provides us with a built-in explanation of why adherents of Kaplan's thesis are adherents of that thesis even though it is false. In brief, when considering the possibility of successful linguistic communication, they focus on a peculiar kind of context which, although not very common, is one in which the Evans method doesn't work. So if one

Sperber and Wilson (though the point carries over to Recanati): both Sperber and Wilson, and Recanati, posit items whose meanings are contents (albeit at a mental level) but Travis denies that there are any such items - linguistic or otherwise. There may also be a further reason to think this classification is a mistake. These philosophers believe that it is possible to construct a single psychological theory which allows one to predict what contents sentences will have whenever uttered. Travis (e.g. (2013)) clearly thinks that such a theory is not possible. It would require the existence of a particular domain over which true generalizations could be made. Travis seems to doubt the existence of the relevant domain. However, given the definition of occasion-sensitivity with which I'll be working in this paper, the view doesn't entail that such a theory is impossible. So such a view is not a target of the current paper. The target of the current paper is the identification of meaning with character.

8 Travis (2006b) does address an argument put forward in chapter 8 of (Cappelen and Lepore 2005), which may look like the Argument against Occasion-sensitivity. That argument is as follows. Features f1...fn of a context fix the content of an utterance of "Philosophy is fun." To know what content was expressed by the utterance of "Philosophy is fun" one would have to know these features. It would be a miracle if one knew these features. There are no miracles, so one doesn't know these features. So one cannot know the content of the utterance of "Philosophy is fun." Notice first that the view attacked isn't necessarily occasion-sensitivity: such a view is consistent with meanings being characters (which is why I'm not including Cappelen and Lepore among the adherents of Kaplan's thesis). But second, notice that the list of features provided by Cappelen and Lepore is a list of features which (according to some) could determine the content of "Philosophy is fun" in some context or other. It doesn't follow from their so being that they determine the content of "Philosophy is fun" in each context in which it may be uttered. But then the second premise doesn't follow from the first: in order to know the content of an utterance of "Philosophy is fun" you don't need to know all or even most of these features. You just have to know the features that determine the content in that particular context. But then the third premise looks decidedly under-supported. To know just some of the listed features isn't miraculous. Travis' response concedes more to Cappelen and Lepore than I do here. But in any case, since the argument isn't about the relation of meaning and character, it isn't the Argument against Occasion-sensitivity. 
thought it were common then one would think that successful linguistic communication cannot be effected by the Evans method. I close in section 8 with a summary of the discussion.

\section{Occasion-sensitivity: some details}

I have already introduced occasion-sensitivity as the thesis that meanings aren't characters. I want to expand on this so as to avoid otherwise likely misunderstandings. The simplest way to an adequate definition requires us to draw two distinctions. The first distinction is between the meaning of an expression and the content of that expression. Unless we stipulate otherwise, it is an open question whether the meaning of an expression can be identified with, or understood in terms of, content. So for example, although the word "girl" means girl, what is required to count as being a girl, and hence, in the extension of "girl," is a second and distinct question. The meaning of "girl" may fix this but equally it may not. Similarly, the meaning of the word "girl" may fix a function from features of the context in which "girl" is used to contents. But equally, it may not fix such a function. That is also an open question.

The second distinction is between two ways of using the locution "content." I can provide some composition rules which show you how the truth-value of the sentence "a is $F$ " is related to the extensions of the constituent expressions "a" and "is F." From these rules one can derive a biconditional of the form: "a is F" is true if and only if a is F. One can call this biconditional a description of the truth-condition of the sentence "a is F." One can do all this without having given any indication of what condition the world has to be in in order for the sentence "a is F" to be true (because one hasn't given any indication of what it is to be $a$ or to be $F$ ). That is one notion of truth-condition. Another notion of truth-condition requires any statement of a sentence's truth-condition to answer questions which the first notion leaves unaddressed, viz. what conditions of the world would make the sentence true, false, or neither? Call the first notion of truth-condition a compositional truth-condition because it concerns the relation between properties of sentences and properties of their parts, whatever they may be. Call the second notion of a truth-condition a worldly truth-condition because it concerns a property of a sentence which involves the extra-linguistic world in a way that compositional truth-conditions do not. A parallel distinction can be drawn for the contents of other expressions. So more generally we can speak of the compositional content of an expression and the worldly content of that expression.

We can now define occasion-sensitivity as the following thesis:

\section{Occasion-Sensitivity}

The meaning of a linguistic expression is not a function from features of a context to worldly contents of that expression.

When I speak of "character" I mean to speak of such a function. The function in question may be a constant function so that the content of an expression is the same in all contexts. ${ }^{9}$

9 MacFarlane (2009, p. 246) makes the following proposal: the content of an expression is not a function from worlds (and possibly times) to extensions, but rather, a function from worlds and values of a counts-as parameter (and possibly times) to extensions. Changes in the value of the counts-as parameter are not to be understood as changes in the condition which that of which we speak must meet in order for what we say about that of which we speak to be true. Changes in values of the counts-as parameter are changes in what aspect of that of which we speak (i.e. the world, broadly speaking) we are speaking about. So, for instance, just as we can make claims about what is so in a given place at different times, so too (according to MacFarlane), we can make claims which are about what is so in a given place, at a given time, when this 
Given this definition we can acknowledge two facts about occasion-sensitivity. Firstly, occasion-sensitivity is not the Davidsonian (1986) idea that the meanings of linguistic expressions are in constant flux. It is a claim about what meaning, when invariant, does. So the thesis that words have context-invariant meanings is simply not under threat from occasion-sensitivity. No one is denying that there is a significant difference between someone who has learnt the meanings of various Estonian words and someone who has not. The question to which occasion-sensitivity is an answer is whether learning no more than their meanings (and syntax) sums up to a knowledge of the contents of expressions in context. Secondly, occasion-sensitivity does not preclude invariant relations between meanings and compositional contents. Formal semantics however is, by and large, concerned only with compositional contents. No formal semanticist constructs descriptions of what precisely counts as being red, a woman, weighing 80 kilos etc. So in denying that linguistic expressions have characters that deal in worldly contents, occasion-sensitivity is not in conflict with the discipline of formal semantics. ${ }^{10}$

We're interested in whether Kaplan's thesis is true. With the foregoing clarification of occasion-sensitivity, we can now be more precise. The meanings of linguistic expressions leave open exactly what (worldly) contents those words have in context (or so I am supposing for the purposes of this paper). For instance, the meaning of "black" leaves open whether the following objects fall within the extension of the word's extension: a kettle made from normal aluminium but soot covered; a kettle made from normal aluminium but painted black; a cast iron kettle that is glowing in the heat; a kettle made from cast iron but enamelled white on the inside (or alternatively, outside); a kettle made from cast iron with a lot of brown grease stains on the outside (cf. (Travis 1985:197)). The meaning leaves this open. Consequently, it leaves open what the worldly content of "black" is. The question we're interested in is this. Although the meanings of linguistic expressions leave this much open, is it possible for a hearer to be in a position to know what (worldly) proposition a speaker intends by her sentence when the hearer observes that speaker utter the sentence (in context) only if the meanings of linguistic expressions are characters (i.e. functions from features of the context of use of these expressions to worldly contents)? Henceforth when I speak of contents, I mean worldly contents.

parameter has different values. Is this proposal incompatible with occasion-sensitivity? Insofar as it is a proposal about the meanings of words, yes. If occasion-sensitivity is true then even once one fixes all aspects of that of which one speaks (including whatever corresponds to the values of MacFarlane's counts-as parameter), the meaning of an expression that one uses to make a claim about that of which one speaks should leave open what counts as falling within the extension of that expression. But according to MacFarlane, it doesn't. Can we test whether MacFarlane is right? No. For, in order to check whether intuitive extensions behave as he predicts, we need to know when each aspect of that of which one speaks changes. We need to know this so that we can check whether, even once they are held constant, the intuitive extension of an expression with a given meaning can change with changes of context in which that expression is used. We do know, it seems, when worlds change and when times change. But we don't know when whatever corresponds to the counts-as parameter changes. So until more is said about what corresponds to the countsas parameter, MacFarlane's hypothesis, although (if understood as a claim about meaning) incompatible with occasion-sensitivity, is (in this respect) untestable.

10 See (Predelli 2005) for a splendid explanation of this. There is an important glitch in Predelli's paper. He writes as though, in showing that occasion-sensitivity and formal semantics are consistent, he is undermining Travis' (1985) claim that the truth of occasion-sensitivity has exciting consequences for semantics. By "semantics," Travis doesn't seem to have meant formal semantics (even if formal semantics is sometimes called "truth-conditional semantics"). Travis seems to have meant the project of reducing meaning to content and/or character proposed by the likes of Lewis (1975) and the early Davidson (1967). Nonetheless, Predelli aptly explains why occasion-sensitivity is not incompatible with formal semantics. 


\section{Conventional contents}

The character hypothesis implies something about the way in which the content of an expression depends upon the context of use of the expression. If the character hypothesis is true then the way in which content depends upon the context of use is a conventional property of that content.

Something is a conventional property of an object if that object has that property because it is treated as having it by a particular class of agents. For an object to be treated as having a given property is for a given group of agents to behave as though that object has that property. For example, the lamp post outside 22 Haddon Road had the property of being a goal post during the kids' football game last Tuesday evening because they so treated it. It gained that property because of its treatment. Other properties are not conventional. The lamp post would be made of steel no matter how much the kids tried to treat it as made of jelly.

The character hypothesis identifies the meaning of an expression with a character. The meaning of an expression is a conventional property. ${ }^{11}$ When I learn the meanings of Estonian words, I consult Estonians. Their judgements about what words mean are definitive. If they change, then so do the right answers to questions about the meanings of words in Estonian. So if the meaning of an expression is a character then the latter must be a conventional property of the expression as well. "naine" in Estonian means woman insofar as speakers of Estonian so treat "naine." If the character hypothesis is true then Conchita Wurst doesn't fall within the extension of "naine" in a given context insofar as speakers of Estonian so treat "naine" in that context.

The fact that the character hypothesis implies that the content of an expression in context is a conventional feature of that expression will prove important for showing that there is a method for communicating which doesn't require the character hypothesis to be true; something I will attempt in section 6. For I will show this by showing that the method doesn't rely on the conventional properties of a linguistic expression and hence, given this implication, any purported meaning-cum-character of that expression.

\section{Practico-Normative Properties}

In order to describe the way of communicating linguistically which I will describe in section 6 , I need to draw attention to a kind of property that an object can acquire from being employed within an action. As we'll see in section 5, linguistic expressions can have contents in context which are properties of this kind. Describing this kind of property is the task of the current section.

11 At least, that seems to be a fairly plausible assumption with a long history; cf. (Austin, 1950, pp. 118-119), (Frege 1892), (Locke 1689 book III, chapter 2), and (de Saussure 1916, p. 67). Notably, in addition to committing themselves to Kaplan's thesis, most of the adherents of Kaplan's thesis each commit themselves to this further thesis. Kaplan (1989, p. 523) takes meaning to be constituted by linguistic conventions. Stenius (1967, p. 262) does the same. Lewis $(1969$, p. 1) takes the thesis as his starting point. Dummett (1986, p. 474) uses "meaning" interchangeably with "conventional significance" and that which is known when one has "knowledge of a language." Hornsby (2009, pp. 108-109) and Reimer (2004, pp. 320-321) lay out the position they seek to defend (the one which Davidson (1986) attacks) according to which the meanings of expressions are conventional properties of those expressions. 
There are things one does which one does in order to do or be doing something else. For instance, one is at the swimming pool. One kicks one's legs and moves one's arms in order to propel oneself forward or so that one is moving forward. Or similarly, one types on the keyboard in order to produce a chapter or so that one is typing a chapter. I am going to use the terminology of "means" and "ends" to describe this. A means does not have to be temporally prior to the achievement of the end. They can be coincident. We already have two examples of this: kicking legs to be swimming; typing on a keyboard to be writing a chapter. Let us say that if one does A in order to do or be doing B then B is one's end and A is one's means. One's ends give one reasons to do things which are means to those ends and reasons to avoid doing things which thwart one's ends. Someone who is rational will act in accordance with what they have reason to do and to avoid doing. For example, if an end of mine is to stay alive, then I have a reason to walk across a busy main road only when the traffic is clear. If I want some food then I have reason to do something that will result in me being in the state of having some food, e.g. going to the fridge.

There are two features of actions related as means to ends which I want to register. The first is this:

\section{End Dependence}

With changes in one's ends, there are changes in the status of activities as means to one's ends.

Only certain activities will result in certain ends. If I want to get to King's Cross then the taking of only certain buses will be a means to that end. If I want to go to Camberwell then those same buses will not be a means to that end. If I want to stay where I am, no (operating) bus will be a means to my end. The second feature is this:

\section{Circumstance Dependence}

With changes of circumstance, there are changes in the status of activities as means to one's ends.

For example, whether, in walking, I am walking north depends upon whether I have my bearings right. If I took a wrong turn then unbeknownst to me I would be walking south rather than north. In walking or by walking I am not then walking north. Whether my walking is my doing that depends upon the circumstances. There is a sense in which, even when in some sense I am not walking north, I can still be said truly to be walking north. Suppose for instance that I have to take a minor road which goes back on itself slightly. I could still report that I was going north if someone was trying to check my general movements, and so where I will be in the next 20 minutes. Precisely when one can no longer be said to be walking north will depend partly, it seems, on what is meant by "walking north" in the context in which one is said to do so, and partly on just how badly one deviates from doing what one needs to be doing in order to be (doing what counts as) walking north. So there are complexities here. But I want to bracket these for the purposes of this paper (though for discussion see (Anscombe 1957) (especially sections 31 and 32) on different ways of falsifying an intention, and (Falvey 2000)). Despite these complexities, it is nonetheless true that whether a given activity is a means to a given end depends, in part, on the circumstances in which the activity is done.

Someone who is pursuing a given end has reason to pursue means to that end and she has reason to avoid doing things which are not reasons to that end. Thus, given end and 
circumstance dependence, what a rational agent has reason to do will change with changes in end and circumstance. Here are two examples.

First, suppose that by moving the window one is moving a patch of light across the wall. If one moves the window without any intention of moving the patch of light, then whether the patch of light is moving across the wall, and what would be required to make that happen, and keep that happening, furnish one with no reason to change how it is that one is moving the window. But if one is moving the window with this intention then one's circumstances furnish one with reasons to move the window in different ways depending upon what would be required, in the circumstances, for one to be moving the light across the wall by moving the window. So for instance, there may be some ways of moving the window which aren't instances of moving the patch of light across the wall. Perhaps, it is only when the window is at certain angles that any light is cast on the wall at all from the window. So one ought to move it only within a certain range of angles.

Here's a second example. Suppose one is sitting in a boat, in the sea, with the engine running. If one is moving the rudder in order to sail to the Isle of Wight then one ought to move the rudder in a way which is coordinated with various features of one's circumstances. One's circumstances give one reasons to change how one is handling the rudder, if one has this end in these circumstances. For example, with changes in the currents and the wind, there will be changes to whether turning or holding the rudder in a given location will be for one to be sailing to the Isle of Wight. For the agent to continue to be sailing to the Isle of Wight by moving the rudder, she must change how she does so in accordance with the dictates of her circumstances. Of course, things will be different if one has a different end which one is pursuing by moving the rudder.

Now, suppose that the means for a given end involves the manipulation of an object: a rudder, a window, etc. The reasons the agent has for doing things will be reasons for using the rudder or window in a certain way. If Sam is sailing to the Isle of Wight and the sea conditions are such and such, then he has reason to move the rudder in a given way. Provided that there are no overriding reasons to do otherwise, it follows that Sam ought to move the rudder in the relevant way. Furthermore, given an implicit relativisation to particular agents, passivised equivalents follow. If Sam ought to move the rudder in that way, then the rudder ought to be moved in that way by Sam. The subject of the sentence here needn't be restricted to just Sam. The subject can be extended to anyone engaged in the same action in the same circumstances. So we can generalise across a range of agents for which the passivised claim would be true. In this way we arrive at claims such as: the rudder ought to be moved in that way (by anyone engaged in Sam's project in Sam's circumstances).

These passivised statements describe properties of objects which those objects have when their use is enveloped in the pursuit of wider actions in given circumstances. I will call such properties practico-normative properties. They are practical because they are had by objects only insofar as the objects are used in pursuit of a given action. They are normative because they concern the proper use of the object.

A circumstance can vary in the degree to which it provides constraints on means to a given end. For example, if there are two routes that Sam could take to the Isle of Wight, and nothing gives him any more reason to take one over the other, then there won't be a unique way in which Sam ought to use the rudder of his boat. There may be two disjoint ways of using it between which neither her end nor her circumstances provide reason to pick between. The circumstances could provide more constraints on means than this or less. The fewer the 
constraints, the laxer the practico-normative properties of the relevant object, potentially to the point where it doesn't have any such properties. Let's say that when the circumstances provide enough constraints to make only one determinate way of using the object a means to the end pursued in those circumstances, the circumstances are dense.

I want to draw attention to two features of practico-normative properties: one is metaphysical and the other is epistemological. Firstly, the metaphysical feature. Practico-normative properties aren't conventional properties. You cannot make moving the rudder a given way a means to getting to the Isle of Wight by getting everybody to treat it as such. Whether that way of moving the rudder is a means to that end is what it is, no matter what it is treated as being. This metaphysical feature implies the epistemic feature. To identify the practiconormative properties of an object, it would suffice to examine the (dense) circumstances of the object in question. One doesn't need to know what practico-normative properties any particular group of people treat the object as having. If one can identify the ends in pursuit of which the object is being used, and if one knows enough of the circumstances in which those ends are being pursued, and if one can work out what is a means to those ends in those circumstances, then one can know how the object ought to be used (therein). If I watch Sam in his boat, and I know his end is to sail to the Isle of Wight, and I know enough about the currents and the winds, I can know what Sam ought to do with the rudder-I can know what ought to be done with the rudder. Because what Sam or others might treat as a means to an end doesn't change what really is a means to an end, who treats what as a means to an end isn't something one needs to know in order to know the practico-normative properties of the rudder.

\section{Non-conventional contents}

Linguistic expressions are objects which get used in a certain kind of action-speaking. That action is something which functions as a means to various ends. So if what has been said in the previous section is accurate then it should apply to the use of linguistic expressions in speaking. A user of linguistic expressions will have certain ends and will be pursuing those ends in certain circumstances. Because the linguistic expressions will have the status of means to the pursued ends, in those circumstances, only if employed with certain contents and not with others, the language user has a reason to use the linguistic expressions in those ways and not in others. That means, given the transformation to the passive, that there are contents with which the linguistic expressions ought to be used when those ends are pursued in those circumstances. So as an instance of a general case, we have:

\section{PN Hypothesis}

The ends being pursued in the context of use, and the circumstances in which they are being pursued, make an utterance of an expression in that context a means to those ends only if it is used with a given content. ${ }^{12}$

Let's call the content in question the practico-normative content of the expression. It is a content with which an expression ought to be used. There are two features of practiconormative contents of expressions to which I want to draw attention. Each feature corresponds to a feature of practico-normative properties that was described at the end of the

12 Travis seems to endorse the view that the content of an expression in context is its practico-normative content. This is most explicit in (Travis 2013) and in less detail in other places such as (Travis 1996) and in the first chapter of (Travis 2006a). However, that view is never presented as a response to Kaplan's thesissomething I will do in section 6. 
previous section. Firstly, practico-normative contents are not conventional properties of expressions in context. The character hypothesis would make whether Conchita Wurst falls within the extension of "naine" in a given context something which is determined by how, for instance, Estonian speakers would treat Wurst as being (just like the meaning of the word "naine" in Estonian). But the practico-normative content of an expression in context would not fix the corresponding extension of the expression in any such way. It would be a matter of what is a means to the ends pursued in the context-something about which, in principle, all Estonian speakers could be mistaken or agnostic. Secondly, the second feature of a practiconormative content is that if one is aware of the context of an expression, and one possesses an understanding of what is a means to what end, in the circumstances, then it is possible for one to know the practico-normative content of the expression-for these are the determining factors of that content and how they do so is not fixed by how a class of people (e.g. Estonian speakers) treat them as doing so.

\section{Why Kaplan's thesis is false}

As a reminder, here again is Kaplan's thesis:

\section{Kaplan's thesis}

It is possible for a hearer to be in a position to know what proposition a speaker intends by her sentence when the hearer observes that speaker utter the sentence (in context) only if the meaning of a linguistic expression is a character.

I now want to argue that Kaplan's thesis is false- there is a way in which a hearer could be in a position to know what proposition a speaker intends by her sentence when the hearer observes that speaker utter the sentence (in context) without the meaning of a linguistic expression being a character.

Here is a way in which successful linguistic communication could take place. Suppose that expressions of a language have meanings but those meanings don't fix the contents of those expressions (as explained in section 2). Suppose also that the PN hypothesis is true and finally suppose that for each expression the speaker utters, she intends to express the practico-normative content of that expression in context. Then the hearer can know the speaker's intended content for each expression if she knows the practico-normative content of each expression in the context. ${ }^{13}$ She can know this by identifying the ends being pursued in the context and by examining the circumstances for the constraints they supply on possible means to those ends (as explained in section 5). The contents will compose to form propositions-given a compositional semantics. But then the speaker and the hearer can alight upon the same contents for the same expressions in context even though the meanings of those expressions leave open the contents of those expressions.

The situation is very much like one described by Gareth Evans. A student reads out an essay which we are to suppose requires stating how a car engine works. The student says the sentence, "A spark is produced electrically inside the carburettor," and a classmate says, "He means the cylinder." Of this Evans says:

...to be saying that a spark is produced in the cylinder is what, given his general plans and his situation, the subject should be doing; that is, doing that is what would

13 I'm taking for granted that if you're a language speaker then you are rational and this is something others can know about you. 
conform best with the subject's plans at this moment. The truth which he should have been trying to express at this point is that a spark is produced in the cylinder. (Evans, 1982, pp. 130-131)

The classmate knew what the student ought to have been saying because she knew what the student was trying to do in uttering his sentence and how this constrained what he ought to do with his words. Admittedly, Evans doesn't distinguish between meaning and content whereas we are. So we should restrict talk about what the student ought to have been saying to talk about the contents he should have intended by given expressions in context e.g. to what he should count as being black rather than to which word he should utter ("black" or some other?) or to with which meaning he should use a word. Nonetheless, the common idea is this. If the circumstances of someone's speaking and her ends in speaking are rich enough, then there are ways the speaker ought to be using her words (more specifically: with which contents), and anyone (suitably equipped) could see that that was so who was able to witness the speaking episode and its circumstances. So if the speaker intends what she ought then one can discern what she intends by discerning what she ought to intend. I will call communication achieved by means of the speaker and hearer searching for the practiconormative contents of expressions in context the Evans method of communication (though I do not mean to imply that Evans himself thought we communicate via the Evans method).

The Evans method doesn't require that the conventional properties of linguistic expressions distinguish a particular content from all the contents an expression could have given its meaning. If the PN hypothesis is true then, without them doing that, the speaker and the hearer can nonetheless distinguish one content from all those which an expression with a given meaning could have by searching for the practico-normative content of the expression in its context of use. That task requires knowledge of only the ends pursued in the context and the circumstances which bear upon the means to those ends: those together fix the practiconormative contents of the expressions in that context. The way in which ends and circumstances determine what would be means to those ends is not conventional: again, you cannot make a certain way of moving the rudder of the boat a way of sailing to the Isle of Wight just by getting everyone to agree to treat it as though it is. For this reason, the task facing interlocutors who deploy the Evans method does not require knowledge of what any class of agents (e.g. Estonian speakers) would count as the (practico-normative) content of those expressions in context. They are what they are regardless. Hence the Evans method can be deployed without appealing to the conventional properties of linguistic expressions. Meanings-cum-characters are conventional properties of linguistic expressions. So meaningscum-characters don't play any role in the Evans method. But then the Evans method can be successfully deployed even if the character hypothesis is false. We can conclude then that the Evans method is a way of engaging in successful linguistic communication which doesn't require the character hypothesis to be true. It is a way of utilizing the non-conventional properties of linguistic expressions in context for the purpose of successful linguistic communication. If so then Kaplan's thesis is false and the Argument against Occasionsensitivity is unsound.

However, the Evans method can be deployed only if the PN hypothesis is true and the PN hypothesis is true only if the context of use of an expression is dense. Whether this is true can change with the context in question. For the Evans method to be a viable method of communication, it's going to need to be the case that contexts of use are dense in the circumstances wherein linguistic communication can be successful-as I will put it, contexts need to be typically dense. I will spend the remainder of this section discussing the assumption that contexts of use are typically dense. 
To find out whether contexts of use are typically dense requires an empirical investigation. We would need to investigate the ends pursued by speakers when they speak and the circumstances in which they do so. The aim of such an investigation would be to discover whether the ends pursued by means of speaking, and the circumstances in which speakers do so, provide sufficient rational constraints on the contents of linguistic expressions in context for linguistic communication to be successful even if meanings aren't characters. That sort of investigation would look a lot like the investigation carried out by (Austin 1962). One looks for "the gap between cup and lip"- one looks for what participants count as successes and failures at doing what they were aiming to do by speaking. There are sociologists who study this with something like Austin's method. ${ }^{14}$ They claim that rich norms govern particular locales for talk which greatly constrain what the rational agent would even attempt in such circumstances. ${ }^{15}$ If that's right then plausibly typical circumstances of speech are dense. But again I emphasize that this is a question to be answered by an investigation into the normative structures of particular social environments - it is not a question that can be answered by those who have never looked. ${ }^{16}$

Nonetheless, here's one reason why one might think that the assumption that contexts of use are typically dense is a non-starter. Informal conversation-one might think-just is to chat without any real further purpose. Surely, one might propose, those contexts are not dense with requirements that would motivate a rational agent to use her words with only certain contents and not others (cf. Lewis 1969, p. 180). However, though I cannot argue the point (for reasons given in the previous paragraph), I suggest that this impression is born of a bad memory. In informal contexts (e.g. a friend's party), there are things that one is aiming to do by speaking: joke, flirt, suss-out someone's character, entertain, debate politics, be polite, ridicule, show concern, and so on. That one is under a pressure to do these things with reasonable competence is strongly suggested by the fact that sometimes one just isn't up to it. Sometimes one knows that one wouldn't know what to (intend or try to) say in the context of the party (or other informal environment). It's not that one would have nothing to say in the sense that one wouldn't be able to find some proposition or other to try to express in that context. One could easily do that. The problem is rather that one wouldn't know which ways of speaking would be a way to do what one feels under pressure to do in that context. So even if we might call a context "informal," that doesn't mean that in that context there aren't ends one ought to be pursuing by speaking therein-ends for which it can be a challenge to find the means.

\section{Why is Kaplan's thesis endorsed?}

14 See (Goffman, 1956, p. 265), (Garfinkel, 1963, p. 187) and (Schegloff, 2007, p. 20) for statements of the "cup-and-lip" method.

15 See Goffman's (1963, p. 58) discussion of "the rule against "having no purpose” or being disengaged." Since Goffman, two fields within sociology have grown around the study of the actions and norms of small social contexts: conversation analysis and ethnomethodology. For an introduction to conversation analysis see (Schegloff 2007). For a recent taster of work in ethnomethodology see the papers collected in (Linstead 2006).

16 In their discussion of metalinguistic disagreements - disagreements about with what content an expression ought to be used in context-Plunkett and Sundell (2013) propose that such disputes are not settled by appeals to linguistic convention. In many cases, they are settled by non-linguistic factors. They call the study of the factors that fix with what content an expression ought to be used in context "conceptual ethics." Insofar as it is empirically grounded, the burgeoning literature on conceptual ethics (cf. (Burgess and Plunkett 2013)) could form part of the investigation needed to ascertain whether contexts of talk are typically dense. 
To the extent that contexts are dense, Kaplan's thesis is false. But suppose that when assessing whether Kaplan's thesis is true, one attended only to contexts which are not dense. If one did that then the Evans method would never occur to one as a serious possible way of communicating linguistically because in the restricted range of contexts one is considering, it wouldn't be one.

It so happens that adherents of Kaplan's thesis pretty much always focus upon a context which is not dense. Adherents of the thesis focus on contexts in which a speaker has the sole end of getting a hearer to grasp the proposition she intends to express. Of course, this doesn't mean that, if asked, adherents of Kaplan's thesis wouldn't allow that other ends are perhaps invariantly being pursued by speaking. But I'm interested in their focus when, as seems to be standard, they are not asked.

Stenius (1967) describes a "report-game" in which the sole aim of one participant is to express one of a range of propositions to another participant. He (1967, p.264) proposes that it "is obvious that by means of the report-game A and B have created a small language for communication" and he (1967, p.265) proposes that we can generalize from this case-as if this were an exemplar of ordinary linguistic communication. Lewis (1969) proposes that we can understand linguistic communication as a coordination problem. But in order to do this, he requires us to suppose that a would-be communicator has a preference for using given linguistic expressions with given contents which is affected by nothing other than how her fellow would-be communicator prefers to use such expressions (this is his assumption that we can understand linguistic communication by focusing on situations in which "a coincidence of interest predominates" (1969, p.14)). If so, then whoever speaks is aiming to do no more than get her would-be recipient to grasp a given proposition by the sentence she uttersagain, as if this were the situation we should use as our way-in to understanding ordinary linguistic communication. In response to Davidson, Dummett, Hornsby and Reimer do likewise. Dummett (1986, p. 471) claims that "in the normal case" given that a hearer knows a language shared with a speaker, "there is nothing that his understanding the words consists in save his hearing them"-as if, in typical contexts in which it is attempted, successful linguistic communication consists of the production of sentences and their being heard and nothing more. When discussing the possibility of communication given Davidson's proposal, Hornsby (2009, p. 110) focuses entirely on a case in which the only end of the speaker is to "be taken to mean what one wants to be taken to mean." Reimer $(2004$, p. 323) works with a situation in which a speaker intends to communicate that $p$, ignoring whatever other pressures might impinge upon the speaker in speaking - as though these were irrelevant. Finally, in response to (amongst others) Travis, Stanley (2007, p. 12), when discussing the possibility of linguistic communication, operates with a conception of conversation which can be analysed as "acquiring and conveying information about the world," leaving any other further end optional for the purposes of successful linguistic communication. ${ }^{17}$ It is as though the adherents of Kaplan's thesis have supposed that because alighting upon the same proposition for the same sentence is required for successful linguistic communication, this much must be

17 With some irrelevant complications (i.e. second order intentions), the communicative situation upon which Grice (1957) chooses to focus is also of this kind. This is consequential. It is not usual for those who abandon the idea that linguistic communication is enabled by regularities in conventional properties to opt (in its stead) for the view that the content of an expression in a context is what the speaker intends it to be, where this intention bears the features sketched by Grice. For example, Davidson (1986) does this and as a result, for the reason put forward in this section, he makes something of a mystery out of how linguistic communication is supposed to proceed. 
achieved before anything can be done by means of communicating and hence that it can be done in principle without doing anything by means of communicating.

In the context focused upon by the adherents of Kaplan's thesis, the exchange of propositions is all that anyone is interested in achieving. The interlocutors will be successful in this aim, no matter the other features of the context, provided that the speaker associates a given content with a given (meaningful) expression if and only if the hearer does likewise. There are many ways that this aim could be met because for any one meaningful expression, there are many contents it could have and any assignment of contents to expressions will be a way of fulfilling the aim. So, no matter the further features of the context, having this aim alone leaves open the means for achieving it - there are many. But then such a context isn't dense. Hence, in such a context, the PN hypothesis isn't true. But then the Evans method of communication cannot be executed in such a context.

However, this fact should be of concern to an adherent of the Evans method only if the contexts upon which the adherents of Kaplan's thesis focus are typical. Although whether typical contexts of talk are dense is a question that requires investigation, it is unlikely that typical contexts of talk will fail to be dense on account of speakers' having ends as pathologically limited as they are in the context upon which the adherents' focus. To clean a context of further ends you have to go to quite some lengths. Suppose you utter a sentence to someone. Suppose you use "harimatu" in your sentence and both you and your interlocutor speak Estonian and so know that "harimatu" means illiterate or uneducated. However, there are many ways that someone can be illiterate. With different such ways, are different contents for "harimatu." Suppose that you intend to use "harimatu" in a sentence to express the proposition that David Cameron is illiterate in one of these ways and that your sole aim is to express this proposition. Your act of speech is not anchored in anything in the vicinity or in any other ends you might have. You have no reason to use "harimatu" with the content you intend as opposed to any other. You don't even have any reason to speak to the person you're speaking to, as opposed to any other, and certainly no reason to get them in particular to entertain the proposition that you intend by your sentence-or any other proposition for that matter. If we take this description of your action seriously, we can see that your act of speech is similar to the acts of someone who "weeps or is acutely apprehensive without apparent cause, or who burns his personal belongings, or who tears up his postal-savings certificates, or who dips the Bible in a bowl of water..." (Goffman 1963, p. 76). Your action is eerily detached from its surroundings.

However, we are not normally met with such detached behaviour. We do not, as a matter of habit, without either our circumstances or our observable actions betraying some purpose in speaking (be it ours or not), utter a sentence to a random individual. Exchanges generally require (possibly non-verbal) introductions. They take place in places which already begin to hint at why we might want to talk to the person we approach. Many take place as part of social events which facilitate certain actions and not others. To find a situation which is abstracted away from all this would require finding an exchange between voices that don't exist in a context that would furnish rational, social creatures like ourselves, with reasons to do certain things and not others. This suggests that the context upon which the adherents of Kaplan's thesis focus cannot be taken as typical of those in which linguistic communication is successful. Of course, it may still be true that contexts of talk aren't typically dense. The current point is only that this can't be because we typically have the blinkered focus (implicitly) presumed by the adherents of Kaplan's thesis. But then the fact that the Evans method fails in such a context cannot be used to discredit that method's status as ours. Nonetheless, and this is why I have discussed the context, the fact that the Evans method 
doesn't work in such a context explains what might attract the adherents of Kaplan's thesis to Kaplan's thesis. For if they focus on such contexts, supposing (as they do) that such contexts are representative of contexts in which linguistic communication is successful, then it would seem to them that the Evans method couldn't be the actual method by means of which we communicate with language.

\section{Sociology}

Let's summarise. To communicate a content by uttering a sentence requires making plain to others what content one intends to express with the sentence. According to the Evans method, one cannot do this "directly": one can as little make plain a given content to others by uttering a sentence and fiercely intending to get others to recognize this as one can make plain that one is waiting for an acquaintance while one loiters in the street by standing there and fiercely intending that others so take one. To make a content that one intends to express with a sentence recognizable to others, one has to visibly integrate one's utterance of the sentence into a wider activity, just as one has to visibly integrate one's loitering into a wider activity. One openly behaves as one who has one's wider aims would have reason to behave.

...when one person comes upon another who is waiting at an entrance for a third, the waiting person may glance at his watch and look up and down the street to give a visible familiar shape to his intention...(Goffman, 1963, pp. 78-79)

Once your act can be recognized as the part of a larger whole that it is, others will be in a position to know what you should be doing, including, what you should be doing with your words. In a slogan, you can communicate linguistically by recognizably doing something else for the sake of which you speak. The possibility of communicating in this way undermines Kaplan's thesis because insofar as your wider actions and circumstances place constraints on what ways of, for instance, being black would make one's speaking a way of pursuing those wider actions, it doesn't require that the meanings of linguistic expressions be characters. One will have sufficient reason to use "black" in a given context with one content over others even if the conventional meaning of "black" in English doesn't supply one with such a reason (given that one is aiming to speak English). This isn't to say that there are never contexts in which linguistic communication isn't possible by means of the Evans method. If one just isn't using one's words as part of any such activity then the intentions one has for them will be obscure to others. An exclusive focus on such contexts will lead one to find certain accounts of communication more plausible than others. But whether what one finds plausible corresponds to what is likely depends on the representativeness of the contexts that are one's focus - an issue that can be settled only by approaching contexts of talk as objects of study and not merely as values of a variable. This doesn't mean that philosophy should "give way" to sociology (pace Goffman 1983, p. 32), but, because the plausibility of a philosophical view can (and in this case does) depend on empirical facts documented in parts of that other field, it might be worth getting more acquainted with that field. ${ }^{18}$

\section{Reference list}

Anscombe, Elizabeth. 1957. Intention. Cambridge, MA: Harvard University Press.

18 The only high profile exchange between a philosopher of language and a micro-sociologist of which I'm aware is the less than friendly exchange between John Searle (1992a; 1992b) and Emmanuel Schegloff (1992) on the rules for conversational turn-taking described in (Sacks, Schegloff, and Jefferson 1974). 
Austin, John. 1950. 'Truth'. Proceedings of the Aristotelian Society: Supplementary Volume 24: pp. 76-116.

Austin, John. 1962. How To Do Things With Words. Cambridge, MA: Harvard University Press.

Burgess, Alexis, and David Plunkett. 2013. 'Conceptual Ethics I'. Philosophy Compass 8 (12): pp. 1091-1101.

Cappelen, Herman, and Ernie Lepore. 2005. Insensitive Semantics: A Defense of Semantic Minimalism and Speech Act Pluralism. Oxford: Blackwell.

Davidson, Donald. 1967. 'Truth and Meaning'. Synthese 17 (1): pp. 304-323.

Davidson, Donald. 1986 'A Nice Derangement of Epitaphs'. In Truth and Interpretation: Perspectives on the Philosophy of Donald Davidson, edited by Ernie Lepore, pp. 433-446. Oxford: Basil Blackwell.

Dummett, Michael. 1986. "A Nice Derangement of Epitaphs": Some Comments on Davidson and Hacking'. In Truth and Interpretation: Perspectives on the Philosophy of Donald Davidson, edited by Ernie Lepore, pp. 459-476. Oxford: Basil Blackwell.

Dummett, Michael.1994. 'Reply to Davidson'. In The Philosophy of Michael Dummett edited by Brian McGuinness and Gianluigi Oliveri, pp. 257-267. Dordrecht: Kluwer.

Evans, Gareth. 1982. The Varieties of Reference. Oxford: Oxford University Press.

Falvey, Kevin. 2000. 'Knowledge in Intention'. Philosophical Studies 99 (1): pp. 21-44.

Frege, Gottlob. 1892. 'Über Sinn Und Bedeutung'. Zeitschrift Für Philosophie Und Philosophische Kritik 100: pp. 25-50.

Garfinkel, Harold. 1963. 'A Conception Of, and Experiments With, "Trust" as a Condition of Stable Concerted Actions'. In Motivation and Social Interaction, edited by O. J. Harvey, pp. 187-238. New York: Ronald Press.

Goffman, Erving. 1956. 'Embarrassment and Social Organization'. American Journal of Sociology 62 (3): pp. 264-274.

Goffman, Erving. 1963. Behavior in Public Places: Notes on the Social Organization of Gatherings. Toronto: Collier-Macmillan.

Goffman, Erving.1983. 'Felicity's Condition'. American Journal of Sociology 89 (1): pp. 153.

Grice, Paul. 1957. 'Meaning'. The Philosophical Review 66 (3): pp. 377-388.

Gross, Steve. 2005. 'Context-Sensitive Truth-Theoretic Accounts of Semantic Competence'. Mind and Language 20 (1): pp. 68-102. 
Hornsby, Jennifer. 2009. 'Davidson and Dummett on the Social Character of Language'. In Knowledge, Language, and Interpretation: On the Philosophy of Donald Davidson, edited by Maria Cristina Amoretti and Nicla Vassallo, pp. 107-122. Frankfurt: Ontos Verlag.

Kaplan, David. 1989. 'Demonstratives: An Essay on the Semantics, Logic, Metaphysics, and Epistemology of Demonstratives and Other Indexicals'. In Themes From Kaplan edited by Joseph Almog, John Perry, and Howard Wettstein, pp. 481-563. Oxford: Oxford University Press.

Lewis, David. 1969. Convention: A Philosophical Study. Oxford: Blackwell.

Lewis, David. 1975. 'Languages and Language'. In Minnesota Studies in the Philosophy of Science 7, edited by Keith Gunderson, pp. 3-35. Minneapolis: University of Minnesota Press. Reprinted in Lewis 1983, pp. 163-188.

Lewis, David. 1983. Philosophical Papers: Volume I. Oxford: Oxford University Press.

Linstead, Stephen (ed.). 2006. The Sociological Review: Special Issue on Ethnomethodology and Sociology 54(3).

Locke, John. 1979. An Essay Concerning Human Understanding, edited by Peter Nidditch. Oxford: Clarendon Press.

MacFarlane, John. 2009. 'Nonindexical Contextualism'. Synthese 166 (2): pp. 231-250.

Plunkett, David, and Timothy Sundell. 2013. 'Disagreement and the Semantics of Normative and Evaluative Terms'. Philosopher's Imprint 13 (23): pp. 1-37.

Predelli, Stefano. 2005. 'Painted Leaves, Context, and Semantic Analysis'. Linguistics and Philosophy 28 (3): pp. 351-374.

Recanati, Francois. 2004. Literal Meaning. Cambridge: Cambridge University Press.

Recanati, Francois. 2010. Truth Conditional Pragmatics. Oxford: Oxford University Press.

Reimer, Marga. 2004. 'What Malapropisms Mean: A Reply to Donald Davidson'. Erkenntnis 60 (3): pp. 317-334.

Sacks, Harvey, Emmanuel Schegloff, and Gail Jefferson. 1974. 'A Simplest Systematics for the Organization of Turn-Taking for Conversation'. Language 50 (4): pp. 696-735.

De Saussure, Ferdinand. 1983. Course in General Linguistics translated by Roy Harris. Gloucester: Gerald Duckworth \& Co. Ltd.

Schegloff, Emmanuel. 1992. 'To Searle on Conversation: A Note in Return'. In (On) Searle on Conversation, edited by John Searle, Herman Parret, and Jef Verschueren., pp. 113-128. Amsterdam: Benjamins Publishing Company.

Schegloff, Emmanuel. 2007. Sequence Organization in Interaction: A Primer in Conversation Analysis, Volume 1. Cambridge: Cambridge University Press. 
Searle, John. 1992a. 'Conversation'. In (On) Searle on Conversation, edited by John Searle, Herman Parret, and Jef Verschueren, pp. 7-29. Amsterdam: Benjamins Publishing Company.

Searle, John. 1992b. 'Conversation Reconsidered'. In (On) Searle on Conversation, edited by John Searle, Herman Parret, and Jef Verschueren, pp. 137-147. Amsterdam: Benjamins Publishing Company.

Speaks, Jeff. 2014. 'Theories of Meaning'. In The Stanford Encyclopedia of Philosophy edited by Edward Zalta. http://plato.stanford.edu/archives/sum2014/entries/meaning/, accessed May 7, 2014.

Sperber, Dan, and Deirdre Wilson. 1986. Relevance: Communication and Cognition. Oxford: Blackwell.

Stanley, Jason. 2007. Language in Context: Selected Essays. Oxford: Oxford University Press.

Stenius, Erik. 1967. 'Mood in a Language Game'. Synthese 17 (3): pp. 254-274.

Travis, Charles. 1978. 'Meaning versus Truth', Dialogue 17 (3): pp. 401-430.

Travis, Charles. 1981. The True and The False: The Domain of the Pragmatic. Amsterdam: John Benjamins.

Travis, Charles. 1985. 'On What Is Strictly Speaking True'. Canadian Journal of Philosophy 15 (2): pp. 187-299.

Travis, Charles. 1989. The Uses of Sense: Wittgenstein's Philosophy of Language. Oxford: Clarendon Press.

Travis, Charles. 1990. 'Critical Notice of Dan Sperber and Deirdre Wilson: "Relevance: Communications and Cognition."” Canadian Journal of Philosophy 20 (2): pp. 277-304.

Travis, Charles. 1996. 'Meaning's Role in Truth'. Mind 105 (419): pp. 451-466. Reprinted in Travis 2008, pp. 94-108.

Travis, Charles. 1997. 'Pragmatics'. In A Companion to the Philosophy of Language, edited by Bob Hale and Crispin Wright, pp. 87-107. Oxford: Blackwell. Reprinted in Travis 2008, pp. 109-129.

Travis, Charles. 2000. Unshadowed Thought: Representation in Thought and Language. Cambridge, MA: Harvard University Press.

Travis, Charles. 2006a. Thought's Footing: A Theme in Wittgenstein's Philosophical Investigations. Oxford: Clarendon Press.

Travis, Charles. 2006b. 'Insensitive Semantics'. Mind and Language 21(1): pp. 39-49. Reprinted in Travis 2008, pp. 150-160. 
Travis, Charles. 2008. Occasion-Sensitivity: Selected Essays. Oxford: Oxford University Press.

Travis, Charles. 2014. 'The Preserve of Thinkers'. In Does Perception Have Content? edited by Berit Brogaard, pp.138-178. Oxford: Oxford University Press. Reprinted in Travis 2013, pp.313-351. 